\title{
Open access to sequence data "will boost hunt for breast cancer gene'
}

London. A sequence of 900,000 nucleotide bases, thought to contain a gene involved in susceptibility to breast and perhaps other cancers, was made publicly available on the Internet last week by scientists at Washington University, St Louis, Missouri, and the Sanger Centre in the United Kingdom.

The move is intended to help research teams on both sides of the Atlantic to locate and identify the gene in question, BRCA2 (breast cancer 2). "The availability of this sequence data will be a significant boost to the search for the gene," says Mike Stratton of the UK, Institute of Cancer Research (ICR), one of the scientists who last year announced that the gene appeared to lie somewhere on chromosome 13.

At the same time, the decision to make the sequence openly available, with no restrictions on how the information is used, reflects the view of those supporting the sequencing work - which include the Cancer Research Campaign and the Wellcome Trust in the UK, as well as the US National Institutes of Health and Department of Energy - that such information should not be treated as private property.

"I believe that the recent scramble to try to lock up [the patent rights to] the sequence of a gene to a single end, and with a single company, is profoundly counterproductive," says John Sulston, director of the Sanger Centre, in a thinly veiled reference to last year's controversy over the decision by the company Myriad Genetics and the University of Utah to apply for a broad patent on the discovery of another breast cancer gene, BRCA1 (see Nature 372, 118; 1994).

"We think the best way to help people to search for and understand the function of the gene is by releasing widely and freely information about the sequence in which it appears to be contained," says Sulston. "The sequence should be openly available for everyone to exploit, not merely to observe."

Since last year's announcement of the

\section{UK court rejects appeal over hepatitis C kits}

London. The medical supply company Murex Diagnostics has lost another round in its worldwide campaign to challenge the patent relating to diagnostic kits for the hepatitis $\mathrm{C}$ virus held by its rival, Chiron Corporation (see Nature 370, 493; 1994).

Earlier this month, the UK Court of Appeal dismissed an appeal by Murex against the decision of a patent judge, $\mathrm{Mr}$ Justice Aldhous, in the summer of 1993, supporting claims by Chiron that Murex had infringed its hepatitis- $C$ patent, and upholding the validity of the patent itself. chromosomal location of BRCA2, Stratton and his colleagues at the ICR have identified a region of the chromosome in which the gene is thought to lie. (Intriguingly, this region is also thought by some researchers to contain a gene - possibly also BRCA2 involved in pancreatic cancer.)

Applying the technique of restriction fingerprinting to clones taken from an artificial chromosome library at Roswell Park Cancer Institute in Buffalo, New York, an ordered array of overlapping clones spanning this region was subsequently put together.

This has enabled the region to be compiled by researchers at Washington University's Genome Sequencing Sulston: patent rush is Sanger Centre, part

of the Wellcome Trust Genome Campus outside Cambridge, which is jointly funded by Wellcome and the Medical Research Council. On 23 November, the preliminary results were made available as an assembled shotgun sequence on the ftp sites of the two research organizations.

Three main research teams are perceived as being in a race to locate BRCA2. The one headed by Myriad Genetics, which many consider won the BRCA1 'race' largely due to the sheer size of its investment in automatic sequencing technology, is considered by many as the favourite. Close behind, however, are Stratton's team at ICR and its collaborators, as well as a consortium at Columbia University in New York which, like scientists at the Sanger Centre itself, has been investigating on the characteristics of chromosome 13

Each of these three groups is thought to

The decision has been welcomed by many patent agents as "good news for the biotechnology industry", as they claim that it helps lay to rest the impression created by several earlier decisions that UK courts are biased against biotechnology patents.

But the verdict is a blow to Murex, which had previously protested that Chiron's successful defence of a broad-based patent had prevented Murex from conducting research into alternative forms of diagnostic kits. The company is now considering whether to appeal to the House of Lords. sequence data for have downloaded the eagerly awaited sequence data after it went on-line at $3 \mathrm{pm}$ last Thursday. But other groups, including one in Japan and another in Texas, are believed to be keen to take up the challenge.

Now the starting gun has been fired, it is up to the rival teams to see who can first identify the gene and the mutations that can cause increased susceptibility to breast cancer. "We have not had any preferential treatment," says Richard Wooster, a member of the ICR team that has localized the gene.

Sulston acknowledges that the decision to provide open access to the sequence which still allows the team that finally identifies any mutations to the gene to apply for the appropriate patents - is an experiment whose outcome is uncertain. "We are taking a risk, and we do not know how the patent lawyers are going to respond," he says.

But he says the Sanger Centre wants to make a deliberate gesture in the controversial debate about how concern for proprietary rights should influence decisions about placing sequence data in the public domain. "We are campaigning for the notion that a sequence as such is 'pre-competitive' [information]," says Sulston.

"It will not be helpful to medicine if, by the year 2003, control of every single gene is tied up by one company or another for 20 years. That would be an enormous ball and chain. It seems obvious that, for the good of humanity, we should try to keep these things in the publicly exploitable domain."

The move has been welcomed by many scientists who expressed concern last year that the award of a broad patent to Myriad meant many others who had contributed indirectly to the BRCA1 discovery would receive neither recognition nor reward. "I am all for sharing information of this kind," says Bruce Ponder of the department of pathology at the University of Cambridge.

But others may have mixed feelings. The decision could backfire, for example, on British sponsors of the sequencing work if commercial returns from the eventual discovery of BCRA2 end up in the hands of a US company. Last year, for example, it was only after the NIH had filed an alternative patent claim on the BRCA1 discovery that Myriad and the University of Utah agreed that the names of two NIH researchers be included on a single, unified application. The NIH is now entitled to a share of the revenue from any commercial product that may stem from the BRCA1 patent.

The BRCA2 data released last week can be found on $\mathrm{ftp} / / / \mathrm{ftp}$.sanger.ac.uk/pub/ human/sequences/13q and on $\mathrm{ftp} / / /$ genome. wustl.edu/pub/gsc1/brca2. David Dickson 